\title{
BASE ON MODEL EXPERIMENT TO STUDY THE EFFECTS OF VERTICAL SPACE ON THE TEMPERATURE OF SOIL MICROHABITATS IN THE PROCESS OF KARST ROCK DESERTIFICATION
}

\author{
YAN, L. B. ${ }^{1}-$ ZHANG, J. L. ${ }^{2}-$ ZHU, S. Y. ${ }^{1}-$ GAO, F. ${ }^{1}-$ YANG, Y. Z. ${ }^{1}-$ HUANG, Z. S. ${ }^{3}-$ YU, L. F. ${ }^{1 *}$ \\ ${ }^{1}$ Research Center of Karst Ecological Environment, The Key Laboratory of Plant Resources \\ Conservation and Germplasm Innovation in Mountainous Region (Ministry of \\ Education)/Collaborative Innovation Center for Mountain Ecology and Agro-Bioengineering \\ (CICEAB), College of Life Sciences/Institute of Agro-Bioengineering, Guizhou University, \\ Guiyang 550025, Guizhou, People's Republic of China \\ ${ }^{2}$ College of Eco-Environmental Engineering (The Institute of Karst Wetland Ecology), Guizhou \\ Minzu University, Guiyang 550025, Guizhou, People's Republic of China \\ ${ }^{3}$ College of Architecture and Urban Planning, Guizhou University, Guiyang 550025, Guizhou, \\ People's Republic of China \\ *Corresponding author \\ e-mail:lfyu@gzu.edu.cn
}

(Received $6^{\text {th }}$ Aug 2019; accepted $31^{\text {st }}$ Oct 2019)

\begin{abstract}
Heterogeneity, the most prominent feature of karst ecological conditions, makes the restoration of areas experiencing Karst Rock Desertification (KRD) difficult. Soil temperature is one of the most important ecological factors creating KRD, but little research on this topic has been conducted. The present study was causing to understand whether the exposure of bedrock during the process of KRD changes the soil temperature of karst microhabitats. Thus, a simulated soil temperature of KRD microhabitat in different time periods and with varied soil thickness was quantified. The results showed that bedrock exposure can change soil temperature. The trend varied with soil depth. In the high temperature period, the exposure of bedrock resulted in heating of soil, but in the low temperature period the exposure of bedrock resulted in cooling of soil. Both soil depth and bedrock exposure have a significant effect on soil temperature. However, the influence of bedrock exposure on soil temperature changed dramatically during different periods.
\end{abstract}

Keywords: limestone, lime soil, soil thickness, exposed bedrock, soil physical properties

\section{Introduction}

Human activities and interference can easily degrade a fragile karst ecosystem that normally degenerates into an area of karst rock desertification (KRD). Ecosystem restoration has proved difficult in areas of KRD (Peng et al., 2008). Also, one main feature of karst areas is that they have shallow soil with a limited total amount, a phenomenon that is exacerbated by KRD. Therefore, KRD results in discontinuous soil cover, a change in the composition of energy conducting media, and enhanced heterogeneity. The smallest classification unit of habitat heterogeneity is the microhabitat level. The earliest classification of karst divided karst microhabitat into six categories: stony surface, stony gully, stony crevice, stony trough, stony cave, and soil surface (Zhu, 1993). Other scholars have proposed more categories or new classification methods (Li, 2002; Yang et al., 2008), but the most widely used classification methods identify six types of microhabitats. Early scholars paid attention to the distribution of 
karst microhabitats as well as their morphological and spatial characteristics of microhabitats by comparing soil temperature, soil moisture, and the light environment of microhabitats (Zhang et al., 1996; Zhu, 2003). Later, scholars paid attention to the relationship between complex microhabitats and biodiversity ( $\mathrm{Yu}, 2006$; $\mathrm{Yu}$ et al., 2007), physical and chemical properties of soil (Tang et al., 2016; Liao et al., 2010, 2012a, b; Liu et al., 2008), and soil ecosystem processes (Hu et al., 2016a, b; Du et al., 2011; Liao et al., 2013).

Almost no research has been conducted on soil temperatures in karst areas because of its need for long-term observations and high temporal resolution; this is complicated by the fact that field conditions are impossible to reproduce, measuring tools are expensive, and older analytical methods were employed in previous studies (Yu et al., 2011; Yuan, 2015a). However, soil temperature is one of the most important ecological factors; it has important effects on the soil microbial community, respiration, and enzyme activity (Yuan et al., 2015b); it will also affect plant metabolic activity. The present study was established to imitate the characteristics of KRD microhabitat which occur on bare bedrock with the goals of filling the gap in research related to soil temperatures in the areas of KRD and discover the effects of KRD on changing ecological factors. The present study compared areas of the soil surface with KRD on bedrock that was not bare by conducting research on the features and regular daily changes in soil temperature under varied meteorological conditions.

\section{Materials and methods}

The typical karst microhabitats soil is shallow (Li et al., 2016). According to the field investigation, it is found that the soil thickness is about $30 \mathrm{~cm}$. To simulate KRD microhabitat, the present study used man-made devices filled with lime soil and limestone having a soil thickness of $5,25,35$, and $45 \mathrm{~cm}$ (The sensor of $15 \mathrm{~cm}$ was damaged by water invasion), it was carried out in Guizhou, China. Plants of Pueraria lobata var. thomsonii were planted in each type of soil, and button thermometers (DS1923, Wdsen Electronic Technology Co., Ltd.) were buried in these devices (Fig. 1).
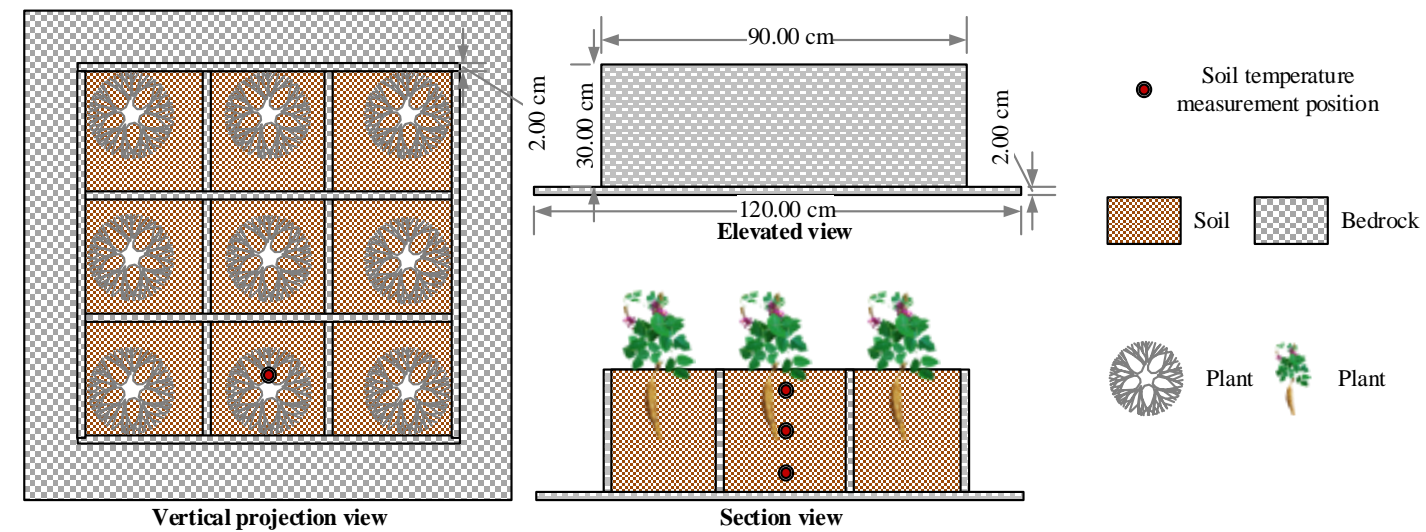

Figure 1. Experimental device, take the soil thickness of $30 \mathrm{~cm}$ as an example

Under natural precipitation conditions, soil temperature at different depths was measured record once per hour. The resulting data that were compared with a natural 
habitat having deep soil and unexposed bedrock. Valid data for 3680 groups data point collections were recorded from 00:00 on July 13 to 23:00 on December 14, 2017. These devices and data were represented by codes representing each type of treatment (Table 1). Data were analyzed and figures were draw using software packages known as change-point (Killick and Eckley, 2015) and ggplot2 (Wickham, 2016) in R software (Team, 2019).

The effects of different sites and layers on soil temperature were analyzed by the method of analysis of variance, and the mean value was tested by $t$-test. Difference markers are marked by Tukey's method.

Table 1. Comparison of the meanings of experimental design codes

\begin{tabular}{c|c|c|c}
\hline Code & Mean & Code & Mean \\
\hline $\mathrm{CK}$ & Experimental control habitat, unexposed bedrock, soil thickness $>1 \mathrm{~m}$ & $\mathrm{~T}$ & Air temperature at $1.4 \mathrm{~m}$ high \\
$\mathrm{O} 1$ & KRD habitat, soil thickness is $10 \mathrm{~cm}$ & A & Depth range is $0-10 \mathrm{~cm}$ \\
$\mathrm{O} 3$ & KRD habitat, soil thickness is $30 \mathrm{~cm}$ & B & Depth range is $10-20 \mathrm{~cm}$ \\
O4 & KRD habitat, soil thickness is $40 \mathrm{~cm}$ & C & Depth range is $20-30 \mathrm{~cm}$ \\
O5 & KRD habitat, soil thickness is $50 \mathrm{~cm}$ & D & Depth range is $30-40 \mathrm{~cm}$ \\
& & E & Depth range is $40-50 \mathrm{~cm}$ \\
\hline
\end{tabular}

\section{Results}

\section{Time series segmentation}

The image (Fig. 2) of air and soil temperature time series shows that during the period from 13 July to 14 December air and soil temperature exhibited a stepwise decline with different amplitudes of fluctuations. Based on the mean and variance of change point analysis the change points were obtained for the critical time points of falling temperatures and the amplitude of the change.
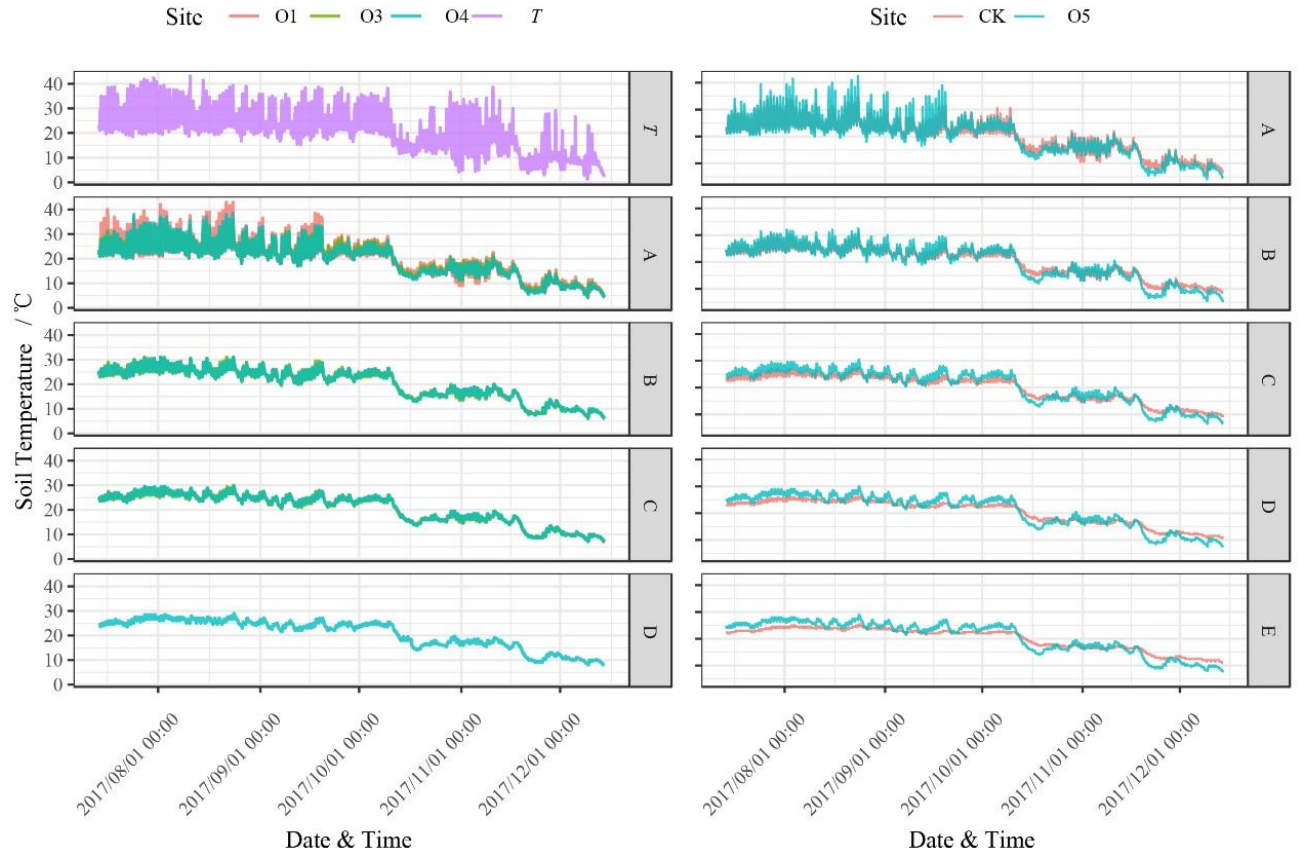

Figure 2. Time series of air and soil temperatures for sites $T, C K, O 1, O 3, O 4$, and $O 5 . A, B, C$, $D$ and $E$ are the soil layer, all abbreviations have the same meaning as listed in Table 1 
The results show that the critical time point was 11 October when the temperature fell and 18 November when the amplitude changes. The two time points were used to divide the air and soil temperature time series to three periods; these were named based on the meteorological characteristics of each period (Table 2). The three periods were the high temperature period (13 July to 11 October), mid-range temperature period (12 October to 18 November), and low temperature period (19 November to 14 December).

Table 2. Meteorological characteristics of three periods

\begin{tabular}{c|c|c|c|c|c|c|c|c|c}
\hline Period & \multirow{2}{*}{$\begin{array}{c}\text { Precipitation } \\
\mathbf{m m} / \mathbf{d}\end{array}$} & \multirow{2}{*}{$\begin{array}{c}\text { Evaporation } \\
\mathbf{~} \mathbf{m} / \mathbf{d}\end{array}$} & \multirow{2}{*}{$\mathbf{T}^{\circ} \mathbf{C}$} & \multirow{2}{*}{$\mathbf{R H} \%$} & \multicolumn{5}{|c}{ Soil temperature ${ }^{\circ} \mathbf{C}$} \\
\cline { 5 - 9 } & & & & $\mathbf{A}$ & $\mathbf{B}$ & $\mathbf{C}$ & $\mathbf{D}$ & $\mathbf{E}$ \\
\hline High & $2.4 \pm 5.1$ & $3.4 \pm 1.2$ & $25.4 \pm 0.1$ & $74.8 \pm 0.4$ & $24.3 \pm 0.1$ & $24.2 \pm 0.0$ & $23.6 \pm 0.0$ & $23.7 \pm 0.0$ & $23.2 \pm 0.0$ \\
Mid-range & $1.9 \pm 4$ & $1.8 \pm 0.9$ & $16.2 \pm 0.2$ & $77.3 \pm 0.6$ & $15.7 \pm 0.0$ & $16.4 \pm 0.0$ & $16.5 \pm 0.0$ & $17.4 \pm 0.0$ & $17.4 \pm 0.0$ \\
Low & $0.6 \pm 1.1$ & $0.8 \pm 0.5$ & $8.9 \pm 0.2$ & $80.5 \pm 0.6$ & $9.8 \pm 0.1$ & $10.8 \pm 0.0$ & $11.3 \pm 0.0$ & $12.4 \pm 0.0$ & $12.8 \pm 0.0$ \\
\hline
\end{tabular}

T: air temperature; RH: relative humidity; high, mid-range, and low temperature periods were 13 July to 11 October, 12 October to 18 November, and 19 November to 14 December, respectively. The codes for soil depth are provided in Table 1

Each of the three time periods exhibited different climatic conditions. The high temperature period featured more precipitation and higher evaporation rates. The midrange temperature period featured average precipitation, evaporation, and relative humidity (RH). The low temperature period featured less precipitation, low evaporation rates, and high humidity. In the entire soil layer from to top to a depth of $40-50 \mathrm{~cm}$, the soil temperature declined in the high temperature period, and rose in the mid-range and low temperature periods. The temperature differences between the upper and lower soil layers was $1.0{ }^{\circ} \mathrm{C}$ in high, $1.5{ }^{\circ} \mathrm{C}$ in mid-range, and $3.0{ }^{\circ} \mathrm{C}$ in the low temperature periods.

The analysis of variance results (Table 3) showed that temperature of air and every soil layer were extremely significantly $(\mathrm{P}<0.001)$ different in the three time periods. Based on the $F$ value of layers and sites in different periods, the soil layers caused a wide variation in temperatures. However, in the high temperature period, the difference caused by the site (devices with different soil thicknesses) were variable. It was higher than the effects of soil layers in the high (Judging from the F value) temperature period, relatively small in the mid-range temperature period and generally high but lower the lower layers during the low temperature period.

\section{High temperature period}

For find the temperature pattern the soil layer and site, and also based on multiple comparisons using Tukey's honestly significant difference test $(\mathrm{P}<0.05)$, means of temperature were drawn (Fig. 3) and compared. The trend of soil temperature rose in the KRD microhabitat experiment but the CK treatment had reduced temperatures during the high temperature period. In addition, the mean soil temperatures in the O1, $\mathrm{O} 3, \mathrm{O} 4$, and $\mathrm{O} 5$ treatments designed to imitate KRD microhabitats were higher than in the CK treatment.

Differences in air and soil temperature were compared for different soil thicknesses in the same habitat. For the O1 treatment, the temperature difference between air (T, $25.4 \pm 0.12)$ and soil layer A $(25.05 \pm 0.1)$ was insignificant. For the $\mathrm{O} 3$ treatment, $\mathrm{T}$ and temperatures of soil layer $\mathrm{C}(25.1 \pm 0.04)>$ soil layer A $(24.75 \pm 0.07)$, while the 
temperature differences between soil layer B $(25.07 \pm 0.05)$ and $\mathrm{T}$, soil layers $\mathrm{C}$ and $\mathrm{A}$ were insignificant. For the $\mathrm{O} 4$ treatment, T, temperatures of soil layers $\mathrm{D}(25.23 \pm 0.03)$, $\mathrm{C}(25.23 \pm 0.04)$, and $\mathrm{B}(25.11 \pm 0.05)>\mathrm{A}(24.35 \pm 0.08)$. For the O5 treatment, temperatures of $\mathrm{T}$ and soil layers $\mathrm{D}(25.6 \pm 0.04), \mathrm{C}(25.28 \pm 0.04)>\mathrm{B}(24.84 \pm 0.05)$, A $(24.84 \pm 0.09)$, the temperature differences of soil layers $\mathrm{E}(25.17 \pm 0.03)$ with $\mathrm{C}$ and B were insignificant. However, the soil temperature of soil layer E was significantly lower than $\mathrm{D}$; for the $\mathrm{CK}$ treatment, $\mathrm{T}>$ temperatures of $\mathrm{B}(24.23 \pm 0.04)$ and $\mathrm{A}$ $(24.32 \pm 0.06)>\mathrm{C}(23.62 \pm 0.03)$ and $\mathrm{D}(23.77 \pm 0.02)>\mathrm{E}(23.18 \pm 0.02)$.

Table 3. Analysis of variance of soil layer and sites at the three periods: high, mid-range, and low temperature periods were 13 July to 11 October, 12 October to 18 November, and 19 November to 14 December, respectively

\begin{tabular}{c|c|c|c|c|c|c}
\hline & & Df & Sum sq. & Mean sq. & F value & P \\
\hline \multirow{5}{*}{ High temperature } & Layer & 5 & 10563 & 2112.66 & 189.69 & $<0.001^{* * *}$ \\
& Site & 5 & 12292 & 2458.49 & 220.75 & $<0.001^{* * *}$ \\
& Residuals & 45559 & 507400 & 11.14 & & \\
& Total & 45569 & 530256 & & & \\
\hline \multirow{4}{*}{ Mid-range temperature } & Layer & 5 & 7697 & 1539.31 & 232.294 & $<0.001^{* * *}$ \\
& Site & 5 & 454 & 90.82 & 13.706 & $<0.001^{* * *}$ \\
& Residuals & 18847 & 124891 & 6.63 & & \\
& Total & 18857 & 133041 & & & \\
\hline \multirow{5}{*}{ Low temperature } & Layer & 5 & 10219 & 2043.84 & 484.45 & $<0.001^{* * *}$ \\
& Site & 5 & 6267 & 1253.48 & 297.11 & $<0.001^{* * *}$ \\
& Residuals & 12316 & 51959 & 4.22 & & \\
& Total & 12326 & 68446 & & & \\
\hline
\end{tabular}

Differences in air and soil temperatures in different habitats were compared with the same soil thickness. For soil layer A, T $(25.4 \pm 0.12)>\mathrm{O} 5(24.84 \pm 0.09)$ and $\mathrm{O} 3$ $(24.75 \pm 0.07)>\mathrm{O} 4(24.35 \pm 0.08)$ and $\mathrm{CK}(24.32 \pm 0.06)$. The temperature difference between habitat $\mathrm{O} 1(25.05 \pm 0.1)$ with $\mathrm{T}$, O5, and $\mathrm{O} 3$ were insignificant. Soil temperature of $\mathrm{O} 1$ treatment was higher than $\mathrm{O} 4$ and $\mathrm{CK}$. For soil layer B, T > O5 $(24.84 \pm 0.05)>\mathrm{CK} \quad(24.23 \pm 0.04)$, the temperature differences between $\mathrm{O} 4$ $(25.11 \pm 0.05)$ and $\mathrm{O} 3(25.07 \pm 0.05)$ with $\mathrm{T}$ and $\mathrm{O} 5$ were insignificant. The soil temperatures for the $\mathrm{O} 4$ and $\mathrm{O} 3$ treatments were higher than those of the $\mathrm{CK}$ treatment. For soil layer C, T, O5 (25.28 \pm 0.04$), \mathrm{O} 4(25.23 \pm 0.04)$ and O3 $(25.1 \pm 0.04)>\mathrm{CK}$ $(23.62 \pm 0.03)$. For soil layer $\mathrm{D}$, O5 $(25.6 \pm 0.04)$ and $\mathrm{T}>\mathrm{O} 4(25.23 \pm 0.03)>\mathrm{CK}$ $(23.77 \pm 0.02)$. For soil layer $\mathrm{E}, \mathrm{T}$ and $\mathrm{O} 5(25.17 \pm 0.03)>\mathrm{CK}(23.18 \pm 0.02)$.

\section{Mid-range temperature period}

Soil temperature rose consistently in the experimental KRD microhabitats and in the CK treatment during the mid-range temperature period.

Air and soil temperatures were compared in treatments with different soil thicknesses in the same habitat. For the O1 treatment, $\mathrm{T}(16.16 \pm 0.19)>\mathrm{A}(15.23 \pm 0.08)$. For the $\mathrm{O} 3$ treatment, $\mathrm{C}(16.52 \pm 0.04), \mathrm{T}$ and $\mathrm{B}(16.14 \pm 0.05)>\mathrm{A}(15.4 \pm 0.06)$. For the $\mathrm{O} 4$ treatment, $\mathrm{D}(17.05 \pm 0.04)$ and $\mathrm{C}(16.63 \pm 0.05)>\mathrm{T}>\mathrm{A} \quad(15.02 \pm 0.06)$. The temperatures were significantly different between layer $\mathrm{B}(16.23 \pm 0.05)$ when 
compared with $\mathrm{C}$ and $\mathrm{T}$. The temperature of layer $\mathrm{B}$ was lower than that of $\mathrm{D}$ and higher than A. For the O5 treatment, the temperature differences were D $(17.02 \pm 0.05)>\mathrm{C}$ $(16.46 \pm 0.05)>\mathrm{B}(15.77 \pm 0.06)$ and $\mathrm{A}(15.42 \pm 0.06)$, but temperature differences between layer $\mathrm{E}(16.85 \pm 0.04)$ with $\mathrm{D}$ and $\mathrm{C}$ were insignificant; The temperature differences between $\mathrm{T}$ with $\mathrm{C}$ and $\mathrm{B}$ were insignificant, The temperature of layer $\mathrm{E}$ was higher than that of $\mathrm{B}$. The air temperature $(\mathrm{T})$ was lower than that of $\mathrm{D}$ and higher than that of A. For the CK treatment, E $(17.38 \pm 0.04)$ and $\mathrm{D}(17.36 \pm 0.04)>\mathrm{C}$ $(16.48 \pm 0.03)$ and $\mathrm{B}(16.36 \pm 0.04)>\mathrm{A}(15.72 \pm 0.07)$. The temperature differences of air $\mathrm{T}$ with $\mathrm{C}, \mathrm{B}$, and $\mathrm{A}$ were insignificant, and air temperature was lower than layer $\mathrm{E}$ and $\mathrm{D}$.
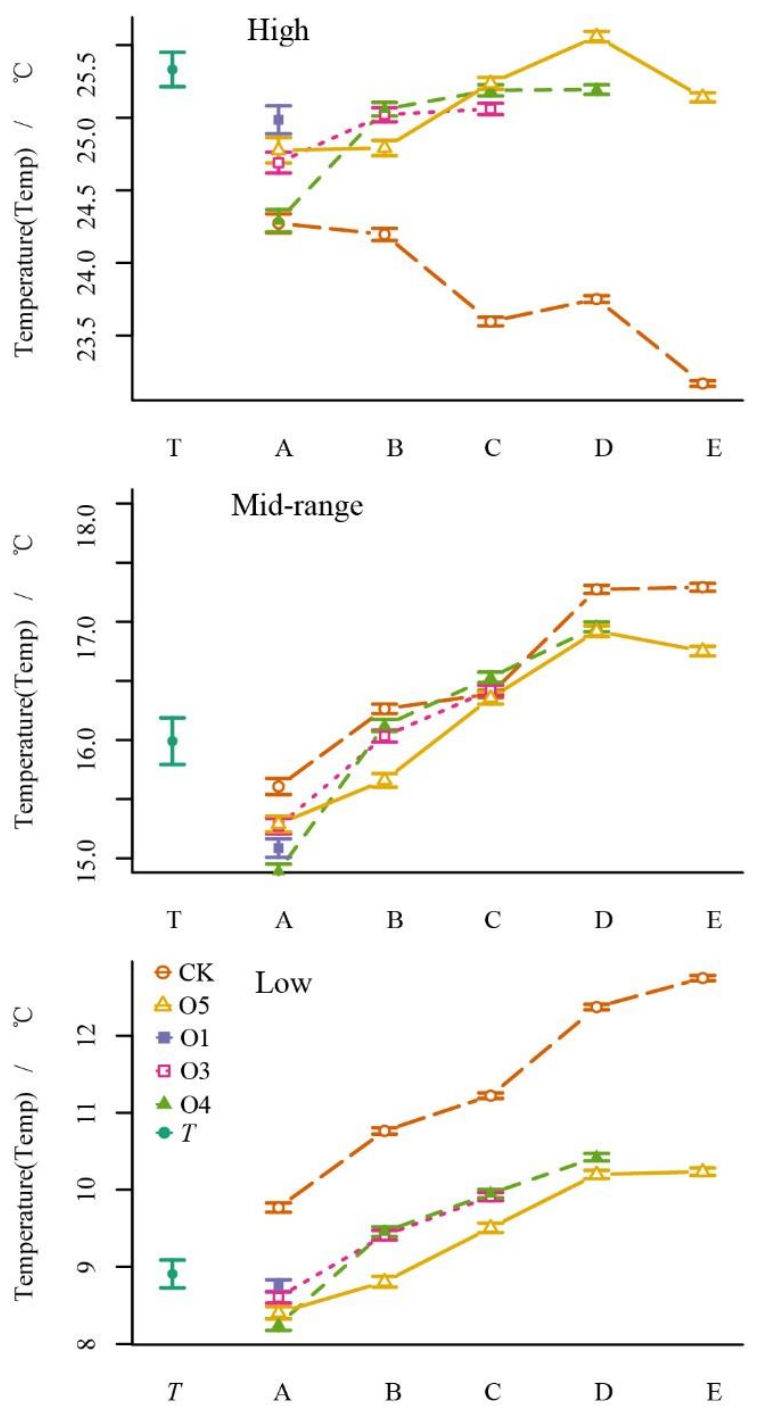

Figure 3. Temperature features of air and soil in the high, mid-range, and low temperature periods: 13 July to 11 October, 12 October to 18 November, and 19 November to 14 December, respectively. T, $\mathrm{CK}, \mathrm{O1}, \mathrm{O3}, \mathrm{O} 4$, and $\mathrm{O5}$ are the sites. $\mathrm{A}, \mathrm{B}, \mathrm{C}, \mathrm{D}$ and $\mathrm{E}$ are the soil layer, all abbreviations have the same meaning as listed in Table 1

Air and soil temperatures were compared in different habitats with the same soil thickness. For the layer A treatment, T $(16.16 \pm 0.19)$ and CK $(15.72 \pm 0.07)>03$ 
$(15.4 \pm 0.06)$ and $\mathrm{O} 5(15.42 \pm 0.06)>\mathrm{O} 1(15.23 \pm 0.08)>\mathrm{O} 4(15.02 \pm 0.06)$. For the layer B treatment, CK $(16.36 \pm 0.04), \mathrm{T}$ and $\mathrm{O} 4(16.23 \pm 0.05)>\mathrm{O} 5(15.77 \pm 0.06)$, but the temperature differences of $\mathrm{O} 3$ with other habitats were insignificant. For the layer $\mathrm{C}$ treatment, $\mathrm{O} 4(16.63 \pm 0.05)>\mathrm{T}$, and the temperature differences of $\mathrm{O} 3(16.52 \pm 0.04)$, CK $(16.48 \pm 0.03)$ and $\mathrm{O} 5(16.46 \pm 0.05)$ with $\mathrm{O} 4$ and $\mathrm{T}$ were insignificant. For the layer D treatment, $\mathrm{CK}(17.36 \pm 0.04), \mathrm{O} 4(17.05 \pm 0.04)$ and $\mathrm{O} 5(17.02 \pm 0.05)>\mathrm{T}$. For the layer E treatment, $\mathrm{CK}(17.38 \pm 0.04)>\mathrm{O} 5(16.85 \pm 0.04)>\mathrm{T}$.

\section{Low temperature period}

The soil temperatures tended to increase in the experimental KRD microhabitats and increased in the $\mathrm{CK}$ treatment during the low temperature period. The difference between the low and mid-range temperature periods was that soil temperature in the experimental KRD microhabitats were lower than the CK treatment in the same layer.

Differences in air and soil temperature with different soil thicknesses were compared in the same habitat. For the $\mathrm{O} 1$ treatment, the temperature difference of layer A $(8.76 \pm 0.08)$ with $\mathrm{T}(8.87 \pm 0.18)$ was insignificant. For the $\mathrm{O} 3$ treatment, $\mathrm{C}$ $(9.96 \pm 0.05)>\mathrm{B}(9.44 \pm 0.06)>\mathrm{T}$ and $\mathrm{A}(8.62 \pm 0.07)$. For the $\mathrm{O} 4$ treatment, $\mathrm{D}$ $(10.49 \pm 0.05)>\mathrm{C}(10.01 \pm 0.06)>\mathrm{B}(9.49 \pm 0.06)>\mathrm{T}>\mathrm{A}(8.26 \pm 0.07)$. For the $\mathrm{O} 5$ treatment, $\mathrm{E}(10.31 \pm 0.05)$ and $\mathrm{D}(10.26 \pm 0.06)>\mathrm{C}(9.55 \pm 0.06)>\mathrm{B}(8.83 \pm 0.07)$ and $\mathrm{A}(8.41 \pm 0.08)$, and the difference in $\mathrm{T}$ with layer $\mathrm{B}$ was insignificant, while $\mathrm{T}$ was lower than layer $\mathrm{C}$ and higher than $\mathrm{A}$. For the $\mathrm{CK}$ treatment, $\mathrm{E}(12.82 \pm 0.04)$ and $\mathrm{D}$ $(12.44 \pm 0.04)>\mathrm{C}(11.28 \pm 0.04)>\mathrm{B}(10.81 \pm 0.04)>\mathrm{A}(9.8 \pm 0.06)>\mathrm{T}$.

Differences in air and soil temperature with different habitats were compared with the same soil thickness. For the layer A treatment, CK $(9.8 \pm 0.06)>01$ $(8.76 \pm 0.08)>\mathrm{O} 4(8.26 \pm 0.07)$, and differences between $\mathrm{O} 3(8.62 \pm 0.07)$ and $\mathrm{O} 5$ $(8.41 \pm 0.08)$ with $\mathrm{O} 1$ and $\mathrm{O} 4$ were insignificant, the temperatures of $\mathrm{O} 3$ and $\mathrm{O} 5$ were lower than $\mathrm{CK}$, differences of $\mathrm{T}(8.87 \pm 0.18)$ with $\mathrm{O} 1$ and $\mathrm{O} 3$ were insignificant, and the temperature of $\mathrm{T}(8.87 \pm 0.18)$ was lower than $\mathrm{CK}$ and higher than O5. For the layer $\mathrm{B}$ treatment, CK $(10.81 \pm 0.04)>\mathrm{O} 4(9.49 \pm 0.06)$ and $\mathrm{O} 3(9.44 \pm 0.06)>\mathrm{T}$ and $\mathrm{O} 5$ $(8.83 \pm 0.07)$. For the layer $\mathrm{C}$ treatment, $\mathrm{CK}(11.28 \pm 0.04)>\mathrm{O} 4(10.01 \pm 0.06)$ and $\mathrm{O} 3$ $(9.96 \pm 0.05)>\mathrm{O} 5(9.55 \pm 0.06)>\mathrm{T}$. For the layer D treatment, $\mathrm{CK}(12.44 \pm 0.04)>\mathrm{O} 4$ $(10.49 \pm 0.05)>\mathrm{O} 5 \quad(10.26 \pm 0.06)>\mathrm{T}$. For the layer $\mathrm{E}$ treatment, $\mathrm{CK}$ $(12.82 \pm 0.04)>\mathrm{O} 5(10.31 \pm 0.05)>\mathrm{T}$.

\section{Discussion}

The changes in the vertical space feature of soil microhabitats may be caused by differences in the thermo-physical properties of soil and bedrock that could make a difference under the same heat release and absorption conditions. In karst areas, the bedrock was mainly limestone and dolomite which develop into a lime soil type. Here, we reviewed their thermo-physical properties based on a review of the literature (Table 4).

Specific heat of soil was calculated according to the formula of Hanks (1992): where $c_{v}=\rho_{b}\left(0.8374+4.187 \theta_{m}\right) \mathrm{kJ} \cdot \mathrm{m}^{-3} \cdot{ }^{\circ} \mathrm{C}^{-1}$ is specific heat of soil, $\rho_{b}$ is soil density, $\theta_{m}$ is volumetric soil water content. The reference range for soil density is $2.21-2.81 \mathrm{~g} \cdot \mathrm{cm}^{-3}$ (Lu, 2006). Soil volumetric water content was based on long-term monitoring data (0$25 \%)$. 
When comparing the thermo-physical properties of soil and bedrock, soil has a greater amount of specific heat, lower thermal conductivity, and slower thermal diffusivity than bedrock. When the same amount of heat is input to soil and exposed bedrock, these features would be make the temperature of bedrock increase more quickly and the thermal energy of bedrock is then transmitted to the bottom more effectively and faster than in soil. This will cause the soil temperature of KRD microhabitats to be higher than soil surface, something that does not occur in KRD microhabitat, unexposed bedrock, and deep soil.

Table 4. Thermo-physical properties of major bedrock and soil types

\begin{tabular}{c|c|c|c|c|c|c}
\hline \multirow{2}{*}{} & \multicolumn{2}{|c|}{$\begin{array}{c}\text { Specific heat } \\
\mathbf{M} \boldsymbol{J} \cdot \boldsymbol{m}^{-\mathbf{3}} \cdot{ }^{\circ} \mathbf{C}^{\mathbf{- 1}}\end{array}$} & $\begin{array}{c}\text { Thermal conductivity } \\
\boldsymbol{W} \cdot \boldsymbol{m}^{-1} \cdot \mathbf{K}^{\mathbf{1}}\end{array}$ & $\begin{array}{c}\text { Thermal diffusivity } \\
\times \mathbf{1 0}^{-\mathbf{6}} \boldsymbol{m}^{\mathbf{2}} \cdot \mathbf{s}^{-\mathbf{1}}\end{array}$ \\
\cline { 2 - 7 } & Range & Mean & Range & Mean & Range & Mean \\
\hline Limestone (Lei et al., 2018) & $1.298-2.396$ & 1.861 & $2.648-5.273$ & 3.742 & $0.886-3.442$ & 2.031 \\
Dolomite (Lei et al., 2018) & $1.497-2.385$ & 1.798 & $1.664-6.327$ & 4.330 & $0.886-3.442$ & 2.481 \\
Lime soil (Zhang, 2007) & $1.85-5.29$ & - & $0.2-1.5$ & - & $0.2-0.5$ & - \\
\hline
\end{tabular}

A higher base soil temperature during the high temperature period in the bare bedrock microhabitats would result in stronger air transfer to roots for plants growing in these areas. These high temperatures will cost more energy to be used by plants and to expend more water to maintain their increased metabolic activity. As a result, the higher temperatures must exacerbate related problems for the plant that limit its ability to survive. Also, to circumvent this restriction, the plant root may find lower temperature soil and deeper underground water by increasing the length of the root system, resulting in a lower root-crown ratio and higher costs.

\section{Conclusions}

When bedrock becomes exposed this can change the soil temperature of karst microhabitat. Bedrock serves for heating karst in summer with high temperature and relatively greater amounts of precipitation and for cooling in winter with relatively low temperature and high humidity. Variations in karst microhabitats has a greater influence during the high temperature period (summer) than the effects of soil depth in the range of 0 to $50 \mathrm{~cm}$. Variations in karst microhabitats have a significant but smaller than the effects of soil depth on soil temperature during the mid-range temperature period (autumn). During the low temperature period, variations in karst microhabitats have a significant and greater effect but the effect is also lower than the effect of soil depth. Furthermore, soil temperatures of KRD microhabitats were significantly different in different seasons.

In the high temperature period, the soil temperatures at the same depth in different KRD microhabitats were higher than at the soil surface microhabitat. The trends of soil temperature changing with soil depth were different for different habitats. For soil surface microhabitat the temperature fell with increasing soil depth, but for the KRD microhabitats, from 0 to $40 \mathrm{~cm}$, temperatures increased with increasing depth. In natural soil surface habitat, soil temperature of any depth was lower than air temperature. But in the KRD microhabitat, the mean difference of soil temperature at a depth of $40 \mathrm{~cm}$ with 
air temperature was insignificant. Soil temperature at a depth of $40 \mathrm{~cm}$ or so in KRD microhabitat may have been at the turning point in the trend of soil temperature changing with depth.

In the mid-range temperature period, the trends of soil temperature changing with depth were same between the soil surface microhabitat and KRD microhabitat, with increasing temperature as the depth of soil increased. At the surface $(0-10 \mathrm{~cm})$, soil temperatures of KRD microhabitats were uncommonly lower than air temperature. But the difference between surface temperature at the soil surface microhabitat with air temperature was insignificant.

In the low temperature period, the soil temperature at the same depth of different KRD microhabitats were lower than that of soil surface microhabitat. The trends of soil temperature changing with soil depth were the same, because temperature increased with an increase in the depth of soil. At the surface $(0-10 \mathrm{~cm})$, soil temperature of KRD microhabitats was lower than air temperature but soil temperature at the surface was higher than air temperature.

This study employed a quantifiable and repeatable experimental device and resulted in an increased level of soil temperature. Future research could also be conducted that is more in-depth. Such research could be designed to consider factors such as rock volume, exposed bedrock area, soil water content, and soil water-holding capacity with a dependent variable of soil temperature to verify the relationships between them. One could also study characteristics of variation over time and the effects of change.

Acknowledgements. This research was funded by the Project of National Key Research and Development Program of China (Grant No. 2016YFC0502604), the National Natural Science Foundation of China (Grant No. 31560187, 51868008), the Construction Program of Biology First-class Discipline in Guizhou (Grant No. GNYL[2017]009), and the Project of Promoted Innovation for Colleges and Universities of Guizhou Province (Grant No. Qian Jiao He Collaborative Innovation [2014]01).

\section{REFERENCES}

[1] Du, X., Wang, S., Rong, L. (2011): Characteristics of foliar $\delta 13 \mathrm{C}$ values of common shrub species in various microhabitats with different karst rocky desertification degrees. Chinese Journal of Applied Ecology 22: 3094-3100.

[2] Hanks, R. J. (1992): Applied Soil Physics: Soil Water and Temperature Applications. Springer Science \& Business Media, New York.

[3] Hu, N., Li, H., Tang, Z., Li, Z. F., Li, G. C., Jiang, Y., Hu, X. M., Lou, Y. L. (2016a): Community size, activity and $\mathrm{C}: \mathrm{N}$ stoichiometry of soil microorganisms following reforestation in a Karst region. - European Journal of Soil Biology 73: 77-83.

[4] Hu, N., Li, H., Tang, Z., Li, Z. F., Tian, J., Lou, Y. L., Li, J. W., Li, G. C., Hu, X. M. (2016b): Community diversity, structure and carbon footprint of nematode food web following reforestation on degraded karst soil. - Scientific Reports 6: 28138.

[5] Killick, R., Eckley, I. A. (2015): changepoint: An R package for changepoint analysis. Journal of Statistical Software 58: 1-19.

[6] Lei, X., Hu, S., Li, J., Yang, Q., Han, Y., Jiang, G., Zheng, J. (2018): Thermal properties analysis of bedrock in Beijing. - Progress in Geophysics 33: 1814-1823.

[7] Li, J. X., Xiong, G. M., Xu, W. T., Xie, Z. Q. (2016): Distribution of shrublands in relation to soil and climate in mid-subtropical China. - Journal of Plant Ecology 9: 393401. 
[8] Li, Y. (2002): Morphological types and their features of Shilin Karst in Yunnan, China. Carsologica Sinica 21: 14-21.

[9] Liao, H., Long, J., Li, J., Yang, J., Feng, Y. (2010): Preliminary study on spatial heterogeneity of soil mineral composition and organic carbon content at different microhabitats that under different vegetation types in karst region. - Carsologica Sinica 29: 434-439.

[10] Liao, H., Long, J., Li, J. (2012a): Effect of different micro-habitats types on organic carbon and labile organic carbon distribution in surface soil aggregates in Chinese prickly ash orchard of karst mountain area. - Journal of Soil and Water Conservation 26: 156-160.

[11] Liao, H., Long, J., Li, J., Yang, J., Feng, Y. (2012b) Distribution characteristics of soil carbon and nitrogen under different vegetation types in micro-habitats of karst dry-hot valley region of South Western China. - Soils 44: 421-428.

[12] Liao, H., Li, J., Long, J. (2013): Effect of vegetation type and micro-habitat on soil active organic carbon and basal respiration in karst dry and hot valley region of Guizhou Province, China. - Chinese Journal of Soil Science 44: 580-586.

[13] Liu, F., Wang, S., Luo, H., Liu, Y., Liu, H. (2008): Micro-habitats in karst forest ecosystem and variability of soils. - Acta Pedologica Sinica 45: 1055-1062.

[14] Lu, H. (2006): Soil Biogeochemical Characteristics in the Process of Karst Rocky Desertification-A Case of Chaeryan Catchment in Guizhou Huajiang Area. - Institute of Geochemi, Chinese Academy of Sciences, Guiyang.

[15] Peng, W., Wang, K., Song, T., Zeng, F., Wang, J. (2008): Controlling and restoration models of complex degradation of vulnerable karst ecosystem. - Acta Ecologica Sinica 28: 811-820.

[16] Tang, F. K., Cui, M., Lu, Q., Liu, Y. G., Guo, H. Y., Zhou, J. X. (2016): Effects of vegetation restoration on the aggregate stability and distribution of aggregate-associated organic carbon in a typical karst gorge region. - Solid Earth 7: 141-151.

[17] Team, R. C. (2019): R: A Language and Environment for Statistical Computing. https://www.R-project.org/. Vienna, Austria.

[18] Wickham, H. (2016): ggplot2: Elegant Graphics for Data Analysis. - Springer-Verlag, New York.

[19] Yang, R., Yu, L., An, M. (2008): Analysis on microhabitat characteristic in karst region-taking Maolan nature reserve as an example. - Guizhou Agricultural Sciences 36: 168-169.

[20] Yu, G., Wang, S., Rong, L. (2011): Microclimate characteristics of different microhabitats in successional stages of Maolan karst forest. - Earth and Environment 39: 469-477.

[21] $\mathrm{Yu}, \mathrm{X}$. (2006): The Study on the Role of Karst Microhabitats in Karst Vegetation Restoration-An Example of the Shilin National Geopark. - Yunnan Normal University, Kunming.

[22] Yu, X., Li, Y., Ma, Z. (2007): A preliminary study on flora diversity of karst microhabitat in Shilin Park, Yunnan, China. - Journal of Mountain Science 25: 438-447.

[23] Yuan, M. (2015a): Study on Soil Temperature and Water Characteristics in Karst Area. Yunnan Normal University, Kunming.

[24] Yuan, M., Li, H., Wang, D. (2015b); Research progress of forest soil temperature in China. - Hubei Forestry Science and Technology 44: 37-41.

[25] Zhang, B., Wei, X., Zeng, X. (1996): A study of microclimate characters of different microhabitats on karst landform forest. - Journal of Guizhou Agric. Coll. 11: 7-10.

[26] Zhang, L. (2007): Theoretical and Experimental Study on Heat and Moisture Transfer in Soil and Ground-Source Heat Pump. - Zhejiang University, Hangzhou.

[27] Zhu, S. (1993): Ecological Research on Karst Forest (I). - Guizhou Science and Technology Press, Guiyang.

[28] Zhu, S. (2003): Ecological Research on Karst Forest (III). - Guizhou Science and Technology Press, Guiyang. 